effective strategy to reduce these crimes would appear to be a strong and visible police presence during the periods of greatest risk.

The computerised Hospital Trauma Registry Project was funded by a grant from the Area Medical Audit Committee of Greater Glasgow Health Board. The Scottish Trauma Audit Group (STAG) was funded by a grant from the Scottish Office Clinical Resource and Audit Group. We wish to thank Ms Sarah Shrouder of STAG for her assistance in data collation for this study.
1 Strathclyde Police report on 'Operation Blade', 1994.

2 Shepherd JP, Shapland M, Scully C. Recording by the police of violent offences; an accident and emergency department perspective. Med Sci Law 1989;29:251-7.

3 Shepherd JP, Scully C, Shapland M, Irish M, Leslie IJ Assault: characteristics of victims attending an inner-city hospital. Injury 1988;19:185-90.

4 Shepherd JP, Farrington DP. Assault as a public health problem: discussion paper. J R Soc Med 1993;86:89-92.

5 Shepherd JP, Robinson L, Levers BGH. Roots of urban violence. Injury 1990;21:139-41.

\title{
EMERGENCY CASEBOOK
}

\section{Traumatic intrapericardial diaphragmatic hernia}

A 69 year old woman was brought to our emergency department after a car accident. The patient was haemodynamically stable and was diagnosed as having a pelvic fracture, a closed tibial fracture, and multiple left sided rib fractures on an otherwise normal radiograph of the chest. Osteosynthesis of the tibia was performed. On the first postoperative day a repeat chest radiograph showed a supradiaphragmatic colonic haustration pattern suggesting the possibility of a diaphragmatic rupture with herniation of colon into the chest. Computed tomography of the chest confirmed the defect in the central part of the diaphragm with intrapericardial herniation of the colon. At laparotomy through a left subcostal incision a $10 \mathrm{~cm}$ tear was found in the pericardial diaphragm. Part of the stomach and the transverse colon had herniated into the pericardium. The herniation was easily reduced and the lacerated diaphragm was repaired with interrupted non-absorbable sutures. Postoperative recovery was uneventful.

$C T$ scan of the chest: intrapericardial herniation of transverse colon due to traumatic rupture of the central part of the diaphragm

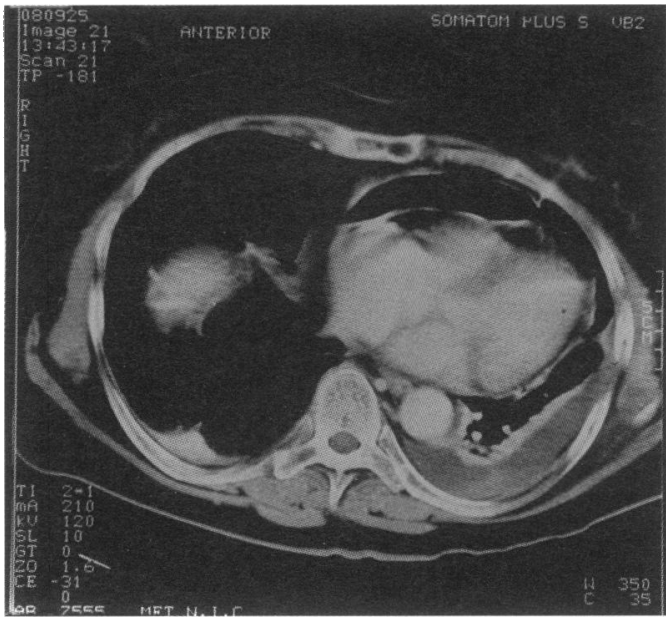

Traumatic diaphragmatic rupture (TDR) results from blunt or penetrating thoracoabdominal trauma and is diagnosed in $0.8-2 \%$ of multiple trauma admissions; an estimated $5 \%$ of patients need a laparotomy after blunt trauma. Isolated rupture of the central part of the diaphragm resulting in an intrapericardial diaphragmatic hernia is almost never mentioned in large reviews of TDR. The literature consists mainly of case reports. Diagnosis was made by chest radiograph 24 hours after admission and confirmed by CT scan. Our case supports the need for serial radiographs of the chest in multiple trauma patients. A high degree of suspicion is needed to allow detection of signs pointing to the possibility of TDR. In more than $50 \%$ of cases diagnosis is made during surgery, either laparotomy or thoracotomy. Traumatic diaphragmatic rupture is practically always combined with associated injuries. The prognosis is determined by the seriousness of the associated injuries. More than half of patients with TDR need postoperative ventilation. There is an overal mortality of $21 \%$ to $41 \%$. F MUYSOMS, H VERHELST, H SCHROË, Department of Vascular and Thoracic Surgery, R DE JONGH, Department of Anaesthesia and Intensive Care, St fansziekenhuis, Schiepse Bos 2, 3600 Genk, Belgium 